\title{
ADVANCES IN PRIOR KNOWLEDGE CONCEPTUALIZATIONS: INVESTIGATING THE IMPACT ON HEALTH BEHAVIOR
}

Danae Manika, Durham University, UK

Linda L. Golden, University of Texas at Austin, USA

\begin{abstract}
Health care marketers should assess the levels of consumers' prior knowledge set before designing health marketing communication messages. Consumer behavior research has established the importance of prior knowledge, yet only part of knowledge directs health behavior. We posit four prior knowledge dimensions which include consumer behavior's prior knowledge conceptualizations (objective knowledge, subjective knowledge), a discrete measure of knowledge use confidence, and introduce the economic psychology concept of what the individual takes to apply to the self (personal knowledge); and we investigate their impact on health behavior for the USA and their relevance for six other countries. Scales were developed and administered via an Internet survey. Across all countries, personal knowledge is important to understanding the relationship between prior knowledge and health behavior. Countries varied in their knowledge use confidence and subjective knowledge. Objective knowledge was associated with health behavior for only one country.
\end{abstract}

References available upon request 